\title{
Problemas de la enseñanza en la epoca de Feijoo
}

\author{
por Dolores CABRE MONTSERRAT \\ Catodrático del Inetituto de E. M, de Tarragona
}

"Operaré con lo leido, porque bueno es hacer pensar sobre lo que han escrito otros...

Fray B. J. FeIJOO

¿Qué debía ocurrir en España, en la primera mitad del s. XVIII, para que Forner, el erudito extremeño, en 1772, definiera a su tiempo como el siglo de los ensayos, siglo de diccionarios, siglo de diarios, de impiedad, de charlatanes?

Una colección de cartas, publicadas ya; ${ }^{1}$ otra manuscrita de la Biblioteca "Menéndez Pelayo", de Santander;" un libro, manuscrito también, de la Biblioteca Provincial de Tarragona, ${ }^{3}$ en el que se recogen sermones, cédulas, decretos; furiosos ataques contra los jesuitas, encerrados

1. Epistolario español, B. A. E., vol. 62.

2. $M 118$ (357 R 1-2-3).

3. M 249. 
en letrillas que quieren ser populares; en pretendidas cartas que Santa Teresa dirige al P. Gracián, y del jesuita P. Bermejo al P. Isla, animándole, con fines no limpios, a que publique la segunda parte de "Fray Gerundio"; pastorales del arzobispo de Valencia, Azpuru. La lectura detenida de las obras del P. Feijoo y de los que tuvieron relación con el directa o indirectamente en los caminos docente y gramatical, han abierto una ventana al mundo efervescente del s. xvirI, que produce, ciertamente, aturdimiento.4

Pero, contemplando el espectáculo a distancia, con la perspectiva del tiempo pasado, no podemos por menos que sentirnos emocionados por las actitudes de algunos de los intelectuales, quienes, llevados por un ideal patriótico, en el que la lengua y la cultura juegan un papel importantísimo, luchan, meditan, denuncian envidias, obstáculos que se oponen a la marcha noble, defectos que hay que corregir y ofrecen remedio. Como si todos los hombres y acontecimientos estuvieran envueltos en una ráfaga de viento que empuja, se corre febrilmente desde los puestos altos. Ilustradora es la expresión de Mayans, quien, en carta a Felipe V, comunica su felicidad «por tener ocasión de representar (a S. M.) la inquietud en que vivon. ${ }^{5}$

Hay una literatura de impaciencias en la que el P. Feijoo será el árbol del que brotarán ramas frondosas. Las más jóvenes, Cadalso y Jovellanos, ofrecerán ideas que sólo madurarán en el s. xx. Todos ellos harán que el balance del siglo xvıII, corrigiendo al autor de las Exequias, arroje cifras muy positivas a su favor, en el orden humano, en el científico y en el de la docencia.

Resulta difícil hacerse cargo de la incultura popular, cuyo panorama presentan negrísimo los escritores del tiempo, al estudiar la cantidad de centros de enseñanza que existían en España desde el s. xvir, en sus tres grados. El s. XvirI tiene sus universidades, ${ }^{6}$ entre las que destacan las de Salamanca, Alcalá y Valladolid, y las no destacadas oficialmente, pero tan ricas en trutos, de Oviedo, Valencia y Cervera. Sus colegios -el Trilingüe salmantino, los Reales Estudios madrileños, los regentados por congregaciones religiosas-, con sus procedimientos y sus luchas con los centros oficiales; los profesores privados, las cofradías - la de San Casiano, de maestros realzada por Felipe V. ${ }^{7}$ Sin embargo, todo ello no

4. «B. A. E.», «Clásicos castellanos», "Clásicos Ebro». Menéndez Pelayo: Hist. ideas estéticas, vol. III.

5. Op. cit, carta 154.

6. La Fuente: Hist. de las universidades, vol. III.

7. Reglamentación de la Instrucción Pública. 
sirve más que para destacar la aportación didáctica, en algún aspecto excelente, de los jesuitas y la de los pocos colegios de escolapios.

Y es que Cadalso nos dice que, para la buena marcha de la enseñanza, hay el obstáculo de una España dividida en clases sociales, de las que una sola, - la media distinguida, a la que llama noble-, constituida por militares, cargos del Gobierno y jurídicos, asistía a la Universidad y a los colegios, donde, con lo específico de sus estudios, aprendía humanidades. La clase alta, poderosa, acababa en los oficios reales y recibía educación en colegios especiales o de profesores particulares, a los que ni respetaba ni atendía. La clase baja seguía el oficio paterno. Algunos eran recogidos por alguna orden religiosa, si tenían talento, o asistían a las escuelas de los concejos, o a una clase particular con algún maestro, que, según el P. Isla - solía ser sujeto que mal aprendía cuatro cosas y las transmitía con un criterio personalísimo.

Jovellanos se plantea, muy adentrado el siglo, con dolor, el problema de la mala educación de la masa, cuando dice que "puede tener una nación algunos o muchos y muy eminentes sabios, mientras el pueblo yace en la más eminente ignorancia».

Junto al problema de las clases sociales, se nos presenta otra dificultad: la poca consideración hacia el docente, al que se retribuye mal; al que no se estimula con protección moral o económica. Que no tiene libertad para imponer métodos propios, sobre todo en los estudios superiores, porque le cortan las alas y ponen dificultades en los ascensos. Ante la falta de protección al buen profesor, Cadalso se lamenta de que no exista un mecenazgo inteligente, por falta de talento y sobra de frivolidad, egoísmo y envidia.

Por si fuera poco, a lo ya citado hay que añadir el mal de las guerras en las que tomaron parte los estudiantes de las Universidades. A ellos se protege con convalidaciones, con adelantamientos precipitados de curso. Se suprimen centros de enseñanza superior. Y, aunque se autorizan traslados de estudios, con validez de los mismos para poder continuar en otras universidades — con lo que la enseñanza superior va adquiriendo una fisonomía cada vez más actual-, no por esto, aquella deja de estar baja de tono.

Pero Feijoo, Torres Villarroel, Mayans, Martí, el P. Isla, Cadalso, también nos presentan al profesor irresponsable que abandona sus clases, que encubre su ignorancia con el orgullo; que desde la primera enseñanza malea al muchacho intelectualmente con la selección de trozos de lectura retumbantes y la arbitrariedad en la aplicación de la mayoría de los tex- 
tos de ortografía, ante los que se sentía con valor para inventar sistemas desaforados; que enseña un cúmulo de reglas pesadas que se tenían que aprender memorísticamente, en apoyo de lo cual estaban los textos de nemotecnia -que vienen publicándose en el tiempo-, atacados por Feijoo.

Si a ello juntamos las disputas filosóficas de las universidades, que pasaban al campo personal, en presencia de los alumnos, en las que los contendientes se hieren con palabras y gestos absurdos. Que, por falta de aclaración del sentido de las palabras básicas de la discusión, se pasaban horas y horas combatiendo puntos que no admitían discusión. El disputar porque sí. El manejo de argucias sofísticas «atestadas de voces facultativas». Docentes de criterio cerrado que hacen exclamar al filósofo Martí: "Pero nada de esto ha bastado a persuadirme, porque conozco el genio de estos bufones que hacen burla de lo que no es ergoteo", y que arrancan a Feijoo quejas, porque ve cómo lo valioso de la disputa, en lo que tiene de bueno para agilizar el entendimiento; de labor catártica frente a otras pasiones que no sean las del saber; como método para esclarecer la hermosa verdad; todo ello se pierde. Porque los alumnos que, como espectadores, podrían sacar una consecuencia equilibrada entre dos extremos, no tienen serenidad y acaban tomando partido por uno de los dos bandos contendientes, aunque no le asista la razón.

Y la falta de textos, y la vanidad de los profesores que obligan al alumno a seguir un dictado prolijo que impide acabar la materia al finalizar el curso, cosa que el P. Feijoo quiere remediar aconsejando, para las enseñanzas filosóficas, el procedimiento de los jesuitas, que imprimen libros con las materias del curso.

Feijoo y los escritores coetáneos realizan un salto enorme al futuro cuando sugieren la selección de alumnos por la que se excluya a los ineptos de una clase general que entorpecen, dándoles una enseñanza elementalísima y dedicándoles a oficios manuales. Cuánto se preocupan por los muchachos que no tienen que seguir estudios superiores, para los que aconsejan la enseñanza de la gramática de la lengua propia, la escritura, elementos de retórica, para cuidar la expresión, y las operaciones aritméticas fundamentales; eliminando el latín y otras materias que carecen de utilidad práctica para el futuro del alumno. ¡Cómo llaman al corazón de los profesores para que den muchos conocimientos útiles y aptos para ser aprendidos por su claridad!

Feijoo se entristece cuando, citando a Marulo, dice que los españoles 
son grandes en ingenio y que, aunque no siempre los profesores tengan la culpa de la ignorancia de los alumnos, el éxito de los mismos depende del profesor. Al hablar de un niño prodigio español, residente en Francia, Feijoo comenta: "Fue así este niño, porque tuvo la suerte de caer en manos de un maestro hábil para la enseñanza.» Y Cadalso, por su parte, piensa que es sensible la falta de educación de la juventud española, "porque es viva y talentuda». Y había tribunales para juzgar, y cátedras, exámenes e inspectores...

Bien tenían que responder al estado de cosas las órdenes dadas por Felipe V, Fernando VI y, sobre todo, aunque posteriores a Feijoo, las de Carlos III. En lo universitario, inspirándose en una petición hecha en las Cortes de Valladolid de 1528, para castigar a los profesores poco ejemplares "por los males que se siguen de ello y el poco caso que se hace de los estudiantes " ${ }^{8}$ ordena el último que la provisión de cátedras sea por regencia de tres años y no permanentes, pagando al docente según el provecho que hubieran sacado los alumnos de sus clases.

Las ansias de renovación en la enseñanza partieron de unos pensadores, y muchas veces se quedaron sin realizar, en los círculos reales, por miserias humanas. Por tanto, a pesar de los esfuerzos, la cultura de la época más unida al P. Feijoo será una cultura de minorías y no popular.

En el mundo variado, movido, del s. XvIII, aparece, como ya hemos visto, opinando sobre las más diversas cuestiones, el P. Feijoo. Innovador, no sólo por el contenido de sus escritos, sino por la estructura de los mismos -ensayos, no consecuciones-, productos de meditación, de observación, con aliento lírico, se mueve entre dos mundos: el de la tradición y el de la novedad que admite, seleccionando con criterio subjetivo. Posee la inquietud por la búsqueda de la verdad sin hurtar el sentido religioso de la misma y por mejorar España; todo ello en un estilo claro, de frase larga o corta, golpeada, según las circunstancias; preciso, con cultismos y galicismos que no dificultan el entendimiento. Consciente del mal que ha causado el intelectual apartado orgullosamente del pueblo, se preocupa por el muchacho, sujeto portador de un alma digna de respeto, que no quiere que se agote sumido en un trabajo monótono y continuado, sin que se le haga alternar el esfuerzo intelectual con el físico y variar, en el estudio, las materias.

A Madrid, donde confluyen los escritores de todas las regiones, llegan vientos fuertes de Levante - Valencia y Cataluña- cargados de clasici-

8. Real cédula 17-I-1771 (Mercurio de enero de 1773), 
dad, y los finos y observadores de Asturias. Hay escritores, opiniones, ideas...

\section{La enseñanza de la lengua}

De todas las enseñanzas que se daban en las universidades, las menos consideradas, si atendemos a las condiciones en que se desenvolvían -profesores volantes con sueldo mísero-, eran las de Retórica y las de Gramática. ${ }^{9}$

Los planes de enseñanza se suceden. Mayans no para de hacer proyectos, que conocemos por su correspondencia con Patiño, con el propio rey, con los personajes reales. Mayans, vivista, redacta planes y, por amor a Cisneros, a quien admira, pide que reorganicen los estudios de Alcalá, creándose cátedra de Jurisprudencia; porque, dice, la situación política de Europa lo exige. Y siguiendo la tradición de los filólogos del siglo XVI, insiste en que se introduzca el estudio de la lengua nativa con su ortografía, con su gramática. Junto a él, los de latín y griego, la retórica y la lógica, en todas las especialidades universitarias.

Ya en el s. Xvi el humanista A. Agustín sustenta que no hay materia de investigación tan eficaz, en los campos histórico y cultural, como el filológico. La lengua es instrumento y vehículo del pensamiento. La vuelta al siglo citado hace que surja potente la idea de elevar a categoría la lengua propia que, ahora, sigue al descenso nacional.

Como en el primer renacimiento, tiene que ser compañera del Imperio; pero, en el s. XVIII, además, elemento facilitador del estudio del latín, que no se suprime de los planes de enseñanza. Mayans escribe a Patiño que una de las cosas que debe procurar una nación es la de que "su lengua sea universal», lo que se consigue, añadirá, escribiendo excelentes libros en el propio idioma, como ocurrió en el reinado de Felipe II. Pero el barroquismo que aún continúa a principio de siglo, los galicismos y las lecturas de malas traducciones, que arrancan lamentaciones al P. Isla y a Cadalso, han despojado a la lengua española de sus

9. La Fuente, op. cil. 
mejores cualidades : el laconismo, la abundancia y la energía que hacían del español una lengua hermosa.

En Feijoo hay la inquietud por problemas que, según él, no ha resuelto la Real Academia con su Ortografía y su Diccionario. Y, aparte las escapadas que realiza a lo propiamente fonético, materia en la que tiene ingenuidades por falta de material de estudio especializado, ${ }^{10}$ se preocupa por ver lo que, según criterio propio, falta o sobra al español para ser una lengua perfecta. Para Feijoo, toda lengua ha de tener propiedad, para lo cual usará las locuciones más naturales y representativas de los objetos. Ha de tener riqueza. El castellano es rico en voces, dirá, $y$, en palabras compuestas, superior al latín. No necesita más que algunas voces facultativas de acción y abstractas que, inexcusablemente, tiene que pedir prestadas al latín, griego y al francés. Toda lengua evoluciona, añadirá Cadalso, como las costumbres; por tanto, a nuevas modas, incorporación de nuevas palabras.

El origen del poco prestigio del español como lengua culta lo encuentra Cadalso en el abuso de la flexibilidad de la lengua, a la que se ha contorsionado; en la abundancia de fraseología; en el apego excesivo de los traductores al idioma original; en la abundancia ridícula de galicismos, de los que se han contagiado los escritores a fuerza de oír y de leer. El propio Feijoo puede considerarse atacado por el mal, que se preocupa por justificar a los puristas como surgido de la necesidad de enriquecer el castellano con palabras que hagan más concisa la frase; por vocablos para expresar ciertos conceptos o para matizar. Manifiesta un decidido afán por seguir una marcha impuesta, ya a fines del s. Xvir, por la que, y hasta su tiempo, se han introducido, entre cultismos y galicismos, más de dos mil palabras nuevas.

Coinciden todos los españoles en pedir que se enseñe el castellano por encima de todo, para facilitar la mejor expresión del profesor y el mejor entendimiento del alumno. Y, como hemos citado ya, para el mejor estudio del latín. Hay el enorme peso clásico del Mediterráneo en Levante y en los dominios de Italia, por una parte; por otra, la consideración del latín como lengua sabia, formativa, que acerca a un mundo que imitaba lo natural, tan amado por los intelectuales del siglo que nos ocupa.

La lengua se organiza en gramáticas. Hasta el año 1771 no ve la luz la de la Real Academia, que será impuesta a las escuelas de enseñanza

10. Discursos («Paralelo de las lenguas española y francesa»), apartados IV y VI. 
primaria del tiempo de Carlos III. Mayans insiste en que la primera que debe aprenderse es la de la propia lengua, que debe ser enseñada racionalmente. Incluso, como hemos apuntado, la latina debe estar escrita y explicada en español. Afirma que los primeros gramáticos fueron griegos y latinos y que de ellos debemos aprender a unir el uso común con el estudio de la analogía escrita. Anuncia la aparición de una Gramática suya más completa, breve y metódica que las que se han publicado.

Sobre los diccionarios, tan convenientes para la ortografía - por cscoger palabras adecuadas para ser usadas por los traductores; por poseer voces inventadas por los escritores y por el pueblo- hablan Mayans, el P. Feijoo y Cadalso. El P. Feijoo critica el de la R. Academia, porque cierra las puertas a las voces vivas. Cadalso exige un diccionario en el que se haga constar el sentido primitivo de cada voz y el abusivo que le han dado los hombres en el trato corriente, y, añade que, un diccionario conveniente, unas buenas retórica, lógica y metafísica prácticas - que podrían constituir la base de una educación pública eficaz y más renponsable moralmente- hacen falta en Europa.

Juan de Iriarte, ${ }^{11}$ en carta al conde de Valparaíso, y Santander, bibliotecario real, en otra a Esquilache, dan a entender que, en colaboración con otros profesores de humanidades, está, el primero, preparando un diccionario latino-español, español-latino, para cuya empresa Iriarte pide tiempo disponible y protección. Según Santander, «la formación de un diccionario en ambas lenguas será muy necesaria... para ayudar al restablecimiento de la latinidad, tan decaída en España». Afirma que los diccionarios existentes son defectuosos por su contenido.

Dejando aparte las reimpresiones de Nebrija y de Juan de Valdés, estudios del P. Sarmiento, tan ricos por lo que a etimologías se refiere, hay historias de la lengua. Feijoo, sin doctrinarismos, opina. Cree que la lengua hebrea es la madre de todas, siguiendo a S. Jerónimo. Mayans, que la diversidad de lenguas proviene del Diluvio. Feijoo, con Kircher, añade al grupo de las románicas, consideradas como tales en su época, - castellano, francés e italiano- el portugués. Afirma que éste es un dialecto latino por conservar voces no corrompidas de la lengua de Roma. La más próxima al latín cree que es la italiana. A ésta seguirá el portugués, que considera hermano del gallego, fundándose en razones históricas. Mayans publica sus Origenes de la lengua en 1737.

11. Cartas 181 y 187, op, cit. 
La ortografía plantea una serie de problemas. Habían trabajado en ella, dice Mayans, Mateo Alemán, que la había tratado con más acierto que Correas, y otros que no tuvieron éxito. Según él y el P. Isla, se vacilaba entre seguir un criterio etimológico, fonético y el de uso corriente, problema ya acuciante en el s. XVI, como leemos en la correspondencia de Zurita con A. Agustín. ${ }^{12}$

En 1728 sale en Valencia una Ortografía de A. Bordázar, profesor de Latín e impresor en la ciudad del Turia. Se le llama "nuevo Manucio». Es buen matemático, además. Se adelantó en unos años a la de la R. Academia (1741). En ella, siguiendo orientaciones de Mayans, después de profundos estudios de la lengua, pretendiendo acercar la escritura a la fonética, escribe su obra fundada en el valor inmutable de los sonidos españoles y en sistemas de aligación y separación de los mismos. Pretende fijar la ortografía, observando en la escritura de los eruditos las letras repetidas y su aplicación. Distingue entre los españoles a los ortógrafos, Mey, J. de León, Mena, G. de Ayala.

Feijoo alaba la obra por tener excelente sustancia, y concisión, propiedad y pureza de estilo. Se muestra partidario de la ortografía fonética, como Bordázar. No hay que decir que Mayans, padre de algunos puntos doctrinales de Bordázar, se siente identificado con lo que escribe y opina éste. En carta al autor, teoriza sobre la materia. Dice que la naturaleza de las letras es siempre fija, y su combinación, invariable. Sobre estos dos polos únicos se debe basar la ortografía. Encuentra criticable en Alemán y Correas que hubieran introducido letras nuevas y apartado otras que estaban en uso, y por apoyar combinaciones falsas. Declara seguir a Varrón y a Nebrija y cree que es fundamental que

"con las mismas letras con que se escriben las sílabas simples se escriban las compuestas, por ser éstas un agregado de simples expresiones, esto es, de indivisibles elementales pronunciaciones sucesivamente conjuntas, a que estando unidas, es necesario que correspondan aquellas mismas letras que corresponderían estando separadas».

Establece veintiséis letras en el abecedario español; todas ellas necesarias y suficientes para no tener que pedir préstamos al latín, al griego o a otra lengua extranjera. Debe ayudarse, el que quiera escribir bien, del diccionario y evitar las combinaciones de sonidos de ambigua pronunciación. Anuncia, en 1737, la aparición inminente de una Orto-

12. Dormer, Progresos de la historia de Aragón, 1680, Opera Omnia, vol. VIl, edic. Lucae D. Cabré: Zurita y el humanismo, Actas C. VII C. de Aragón, 1962. 
grafía propia brevísima con explicación de reglas, y acomodada a la capacidad de los niños.

Entre lo linguístico y lo literario podemos colocar la estilística. Feijoo nos habla de una diferencia de estilos producida por las distintas psicologías nacionales y las individuales. Así, reconoce que el inglés es muy apto para la tragedia "por ser de genio feroz». Para el amor, el portugués. El italiano es muy propio para la poesía, aunque reconoce que la altura de la italiana se debe, más que a la musicalidad del idioma, a la grandeza de los escritores que la cultivan. Por su carácter poco imaginativo, el francés está poco dotado para lo poético, aclarando que le falta entusiasmo y sobra verdad. Refiriéndose al estilo individual, nos dice que «la pasión del pecho manda la pluma». El P. Isla critica a los traductores que vierten al castellano libros en un estilo estrafalario por haber leído obras culto-latino-rumbáticas y media docena de poetas mitológicos. Mayans indica que el estilo debe ser alto sin afectación; erudito, sin impertinencia; culto, sin oscuridad y artificio; ameno, elegante, suave y dulce.

La visión de la literatura se perfila ya. Los PP. Mohedano escriben una Historia de la literatura española muy abundante en noticias, en diez volúmenes. Velázquez, en 1749, escribe unos Orígenes de la poesía castellana, y en 1759, Lecciones gongorinas. Bastero tiene una literatura catalana en 1724. Mayans, además de las biografías de Cervantes, Fray L. de León y A. Agustín, publicó otra sobre su paisano el filósofo Martí. En ella estudia a varios escritores. Luzán entrega su Poética, obra más preceptiva que otra cosa, en 1737 (primera edición). El P. Sarmiento, en 1728, publica su Sátira contra los abusos introducidos en la poesía castellana. Sus Memorias para la historia de los poetas y de la poesía castellana, póstuma, es bastante posterior (1775) a la muerte de Feijoo.

Mayans, en 1734, en carta a Patiño, escribe que es necesario, como antídoto de malos libros, la publicación de buenos escritores que no pudieron realizarlo por sí, ya por haberles sorprendido la muerte, ya por falta de medios económicos. Añade que es preciso que salgan antologías de poetas españoles y de obras griegas traducidas al español, porque la poesía, en frase de Mayans, es más seria de lo que creen muchos. Indica también la conveniencia de renovar y hacer adiciones de obras importantes que quedaron inconclusas, como las de Nicolás Antonio y las de A. de Morales, y de reunir las dispersas de A. Agustín. ${ }^{13}$

13. La edición de Lucae es de 1765-74. 
Con sus opiniones, Feijoo y Cadalso van creando historia de la literatura que alcanza un gran valor humano como estímulo y modelo de generaciones. El primero defiende la existencia de B. del Carpio, frente a Ferreres y se entusiasma con los escritores españoles, que encuentra superiores a los de otros pueblos por la majestad, fuerza y elevación; con la comedia patria, madre de la comedia europea, superior a la de todo el mundo, no por el método y la organización de la trama, sino por su fuerza inventiva. Cadalso ensalza el valor moral de la buena literatura, que puede servir de poderoso lazo de unión entre los pueblos, siempre que se traduzca bien. Para ello da claras y preciosas instrucciones.

Mayans y Feijoo separan la poesía de la retórica que sigue a los estudios de gramática, y que definen como el arte de adornar el discurso. La expresión más simple del cual está en la explicación de clase. Por esto, Feijoo ataca a los profesores que no permiten que el alumno se defienda con sus propios medios expresivos que le habilitan para vencer las dificultades y adquirir soltura en hablar. Tanto le interesa a Mayans la forma de expresión, que anuncia la próxima salida de una Retórica. Quisiera que los tratadistas de la misma ofrecieran dos clases de obras para la docencia: una, sencilla para los niños; otra, metódica, y más «sublime», para adultos iniciados.

La oratoria religiosa tiene un crítico en el P. Isla, cuando nos presenta a un muchacho que "no sabía leer ni escribir y ya sabía predicar». Contrapone al barroquismo de la época unos modelos: Cicerón, Tito Livio, Virgilio, Plauto y Marcial. Entre los más próximos, aconseja a Santo Tomás de Villanueva, a Fray Luis de Granada y al P. Vieyra.

Entre exageraciones y subjetivismos en las selecciones, cabe destacar, en los autores leídos, un notable querer acercarse al equilibrio. Porque, si bien los modelos literarios del s. XviII se buscan entre los autores del s. xvi por su serenidad, por su claridad; por corresponder a una época de grandeza histórica de la patria, con una lengua rica y una obra artística colosal, también se nos habla de los complicados Góngora y Calderón. Y, de cuando en cuando, nos conmueven con adivinaciones como la de Cadalso al juzgar el Quijote: "Lo que se lee son una serie de extravagancias de un loco... Pero lo que hay debajo de estas apariencias es, en mi concepto, un conjunto de materias profundas e importantes». Y la de Feijoo, que encuentra en Lucano un patetismo y un arrebato superiores a los de Virgilio. Y la introducción de procedimientos filológicos del s. xvi, y tantas otras cosas... 
Decía Zurita, en una carta que dirigió a A. Agustín, que lo que se tiene que valorar en una obra es el amor con que se trabaja. Los escritores comentados pusieron mucho amor en su empresa de levantamiento de España y del español; por esto, a falta de muchas consecuciones, tenemos que valorar científica y afectivamente las obtenidas, y el devoto
impulso. 